\title{
Effects of Bimodal Subtitling of English Movies on Content Comprehension and Vocabulary Recognition
}

\author{
Aida Etemadi \\ Department of English Shiraz Branch, Islamic Azad University \\ $2^{\text {nd }}$ door, Lane 8, Martyr Ramezani St., Iman Shomali St., Shiraz 7187914134, Iran \\ Tel: 98-91-730-7799_E-mail: aidasweet24@yahoo.com
}

$\begin{array}{lc}\text { Received: October 13, } 2011 & \text { Accepted: November 22, } 2011 \quad \text { Published: February 1, } 2012 \\ \text { doi:10.5539/ijel.v2n1p239 } & \text { URL: http://dx.doi.org/10.5539/ijel.v2n1p239 }\end{array}$

\begin{abstract}
This thesis is an attempt to study the impact of bimodal subtitling on content comprehension of English movies and vocabulary recognition. Forty four senior undergraduate students studying at Shiraz Islamic Azad University were selected from two intact classes of Tapes and Films Translation course. Two BBC documentary movies (Dangerous knowledge and Where's my robot?), one with English subtitles and the other without subtitles were selected based on the content and level of difficulty of the language. First, both classes watched the same movies, but class 1 first watched 'Dangerous knowledge' with English subtitling and then 'Where's my robot?' without subtitling. To counteract the order effect class 2 first watched 'where's my robot?' and then 'Dangerous knowledge'. After viewing the movies, the participants answered the relevant multiple choice vocabulary and content comprehension questions. The data gathered were subjected to the statistical procedure of paired samples $t$-test. The results clearly indicated that bimodal subtitling had a positive impact on content comprehension of English movies. It can be said that the participants comprehend the subtitled movie better than the one without subtitle. However, for some reasons bimodal subtitling did not have an effect on participants' vocabulary recognition.
\end{abstract}

Keywords: English movies, Bimodal subtitling, Content comprehension, Vocabulary recognition

\section{Introduction}

English movies are available in many countries around the world and are a popular form of entertainment with many students learning English as a foreign language (EFL). Using films to teach a foreign language can help motivate students and remove some of the anxiety of not knowing the language. However, they are not just entertainment; they are also a valuable language teaching tool. The use of movies as a teaching tool is not new in the field of foreign language teaching and learning. Movies not only allow the teacher to introduce variety and reality into the classroom, but discussions based on movie content allow students to bring their own background knowledge and experiences into the discussion. Furthermore, almost everyone finds watching films pleasurable and enjoys talking about them. From a motivational perspective, it seems that movies are a perfect choice for use in a language learning classroom. However, the burden is on the teacher to find ways to make movies an educationally valuable tool for instruction. This medium provides not only rich aural input, but also, the use of subtitles can expose learners to visual input as well. It is the latter type of input which this study will address. As Kusumarasdyati (2005) states, teachers play such movies without subtitles and ask learners to view them while attempting to comprehend the conversations spoken in the target language. However, it is also possible to present movies with subtitles in the native language. With advances in technology, options of how one can watch movies become numerous. Not only can the sound and images be adopted, but the subtitles of various languages are also called for assisting comprehension and language learning.

Subtitles in any language are wonderful tools that let people enjoy films from other cultures and countries, but for language learners subtitles might offer a new path to language comprehension. The National Center for Technology Innovative and Center for Implementing Technology in Education (2010) asserts that for students who are learning English (or another language), subtitled movies can have benefits. The use of subtitled movies has been proved to be more effective at improving overall listening comprehension than non-subtitled movies. 
Students who watch subtitled movies to learn a foreign language have shown improvement in reading and listening comprehension, word recognition, decoding skills, motivation and vocabulary acquisition.

The reading of subtitles must be separated from the "normal" reading of words and sentences printed on a page. Seeing subtitles is perhaps closer to the act of listening than that of reading. The words are shown once, then gone away. The viewer has no chance to go back and refer to an earlier part in the text. Not only do students need to rely on their ability to take in printed material, but also they need to do it very quickly. The addition of subtitled movies to classroom instruction has a further benefit of shifting watching typical classroom movies from a picture-viewing activity to a reading activity, supplying struggling readers with additional reading practice. (National Center for Technology Innovation \& Center for Implementing Technology in Education, 2010, para. 10).

The National Center for Technology Innovative and Center for Implementing Technology in Education (2010) asserts that research has shown that watching movie appears to have a positive impact on comprehension skills, and combining viewing with text, i.e. subtitles, appears to boost vocabulary acquisition. Though most students do well with subtitled movies, the speed of subtitles could pose a problem for very young children or struggling readers. For particularly low-level readers, teachers should consider using subtitled movies where vocabulary is less likely to be difficult. "These programs may include those where the main characters are children or teenagers, animated movies, family programs, or movies with young children in the cast." (para. 7).

In the EFL classroom, the use of foreign language subtitles projected on the screen during viewings of English-spoken movies is common. However, DVD technology now provides the powerful function of selecting various subtitles that can facilitate the listening comprehension of learners with different levels of proficiency and enhance their motivation toward learning the target language. Katchen, Lin, Fox and Chun (2002) characterize six combinations of subtitles as presented in the following sections:

1) Standard Subtitling (L2 audio with L1 subtitles)

2) Bimodal Subtitling (L2 audio with L2 subtitles)

3) Reversed Subtitling (L1 audio with L2 subtitles)

4) Bilingual Subtitling (L2 audio with L2 and L1 subtitles simultaneously)

5) Bilingual Reversed Subtitling (L1 audio with L1 and L2 subtitles simultaneously)

6) No Subtitling (L2 audio with no subtitles at all)

\subsection{Objectives and Significance of the Study}

The present study intends to investigate the effect of bimodal subtitling on content comprehension of English movies and vocabulary recognition of Iranian EFL students. It aims at finding answers to the following research questions:

1) Does bimodal subtitling have any effect on content comprehension of English movies?

2) Does bimodal subtitling have any effect on L2 vocabulary recognition?

As King (2002) states "films provide more pedagogical options and are a rich resource of intrinsically motivating materials for learners." (para. 1). When learners are exposed to films, they can learn some words and phrases used in the films and ultimately improve their target language. Various types of films, such as fiction, science-fiction, romance, horror and historical movies, catch individuals' interests and arouse learners' motivation. Watching films is among learners' favorite activities. As learners who lack interest in learning a foreign language often fail to make progress, films of various types that arouse different individual's interests can be adopted as language learning materials. However, the way one watches movies has a particular effect on one's learning. One way is watching movies with subtitles either in L1 or L2.

By using L2 subtitled movies, students can learn how to pronounce many words. Moreover, subtitles can reinforce the understanding of English context-bound expressions and help learners acquire new vocabulary and idioms. Furthermore, subtitles can motivate learners to study English outside the classroom context by watching English movies, listening to the original dialogues. Finally it allows learners to follow the plot easily; in other words, to enhance comprehension. Some researchers compared the presence and absence of subtitles. One study revealed that the learners interacted more frequently when the subtitles were provided in the listening class (Grgurovic \& Hegelheimer, 2007). Few empirical studies have been conducted to test the effectiveness of bimodal subtitling on content comprehension of movies in Iran. However, the case of vocabulary is different; 
there are a number of studies that investigated the effectiveness of subtitles on vocabulary recognition. Therefore, this study could have significant implication for both teachers and students.

\section{Review of Literature}

\subsection{The effect of subtitles on language learning}

Various studies have investigated the different aspects of the effect of subtitling on second/foreign language learning. Zanon (2006) investigated the contribution of computer-based subtitling to language learning and concluded that subtitling could motivate learners to appreciate the huge amount of content of the film that does not reach the audience when it is presented to them dubbed. In the same vein, Kusumarasdyati (2005) studied the effect of subtitled movie DVDs and found them an effective teaching device to develop the EFL learners' listening skills.

Borras \& Lafayette (1994) incorporated subtitles into short video segments that were integrated into an interactive multimedia course. The participants were able to see and control a video segment with or without same language subtitles. Results indicated that having the opportunity to see and control subtitles positively influences both comprehension and production of language.

Grgurovic \& Hegelheimer (2007) used a multimedia listening activity containing a video of an academic lecture to compare the effect of second language subtitles and lecture transcripts on the comprehension of the lecture. It turned out that students preferred subtitles and used them more than the transcript.

To study the effect of subtitles on film understanding, Grignon, Lavaur, \& Blanc (2005) compared three versions of a film sequence (that is, dubbed, subtitled, and original versions). They found that the dubbed and subtitled versions lead to better performance than the original version.

\subsection{Effect of subtitles on vocabulary learning}

A number of studies have more specifically focused on the effect of subtitles on vocabulary learning. Bird and Williams (2002) conducted two studies examining the effect of single modality (sound or text) and bimodal (sound and text) presentation on word learning. Both experiments led to the conclusion that subtitling can improve the learning of novel words.

In a study, Koolstra and Beentjes (1999) investigated whether children in two primary school grades in the Netherlands would learn English vocabulary through watching a television program with an English soundtrack and Dutch subtitles. They concluded that vocabulary acquisition was highest in the subtitled condition. Two hundred and forty-six Dutch children in Grades 4 and 6 (aged 9+ and 11+) watched a 15-minute documentary having been assigned to one of three experimental conditions: (i) program about grizzly bears with an English soundtrack and Dutch subtitles, (ii) the same program with an English soundtrack but without subtitles, and (iii) a Dutch language television program about prairie dogs (a control condition to establish a baseline of English vocabulary knowledge). These grades were chosen as English classes start in Grade 5, so in Grade 4, they would have had no formal English lessons, while in Grade 6, they would have already had English on a regular basis.

Vocabulary scores for those watching with subtitles were higher than for those watching without subtitles and scores in this latter group were higher than those in the control group. Grade 6 children performed better than those in Grade 4. More words were recognized after watching the subtitled documentary than the non-subtitled version, and, again, Grade 6 children outperformed Grade 4. Children with a high frequency of watching subtitled programs at home had significantly higher English vocabulary scores than children with a low frequency and medium frequency of watching subtitled programs. The findings confirm the many anecdotal accounts that children can acquire elements of a foreign language through watching subtitled television programs. Vocabulary acquisition was also found in children who watched the condition without Dutch subtitles. The findings provided further evidence that the subtitles do not distract from hearing the words.

Stewart \& Pertusa (2004) explored gains in vocabulary recognition made by intermediate students viewing films in Spanish with English subtitles and others watching the same films with Spanish subtitles. They reported that intralingual subtitles are more effective in enhancing vocabulary recognition.

Markham (1999) also examined the effect of subtitles on aural word recognition skills and found that the availability of subtitles significantly improved the participants' ability to identify the key words when they subsequently heard them again (p: 323-4).

\subsection{Effect of subtitles on movie comprehension}

Hinkin, Michael (2009) Performed Two studies to investigate the effects of subtitled movies on the comprehension of movie content. Both investigations involved the presentation of 10-minute movie clips from A 
Few Good Men and See No Evil, Hear No Evil. Participants completed three types of multiple-choice recognition questions for each movie, including: pictorial-only questions, verbal-only questions and combined-information questions. Experiment 1 was designed to investigate the difference between levels of comprehension, when verbal information was presented only in the participants' native language (i.e. English soundtrack and/or subtitles). Results of Experiment 1 indicate that participants performed significantly better on verbal-only and combined-information questions when their native language was present in the subtitles as opposed to the soundtrack. These findings confirm previous findings that reading verbal information in subtitles is more efficient than listening to the soundtrack. Comparison of performance on the pictorial-only questions across presentation formats in Experiment 1 showed participants in the English soundtrack with no subtitles condition performed significantly better than all other conditions. Although Experiment 1 provides a basic understanding of how native language soundtracks and subtitles influence comprehension of movies, subtitled media are primarily used when viewing a movie with verbal information from a foreign language. Experiment 2 built on the results of Experiment 1 by incorporating an unfamiliar language (i.e. French). The question sets used in Experiment 1 were also used in Experiment 2; however, two French vocabulary tests were also used in Experiment 2 to measure incidental foreign language acquisition. Consistent with the results of Experiment 1, participants performed significantly better on verbal-only and combined-information questions when their native language was in the subtitles. This finding extended the conclusion that native language verbal information presented visually (i.e. subtitles) yields better performance on questions requiring verbal cues than native language verbal information presented orally (i.e. soundtrack) to foreign language material. Comparison of performance on the pictorial-only questions across presentation formats in Experiment 2 showed no significant differences. Comparison across the two experiments reflected a distraction effect associated with the presence of a foreign language. Performance on the French vocabulary tests was very poor across all conditions and yielded no significant differences, suggesting that the tasks may have been too difficult.

In a study, published in the open-access journal PLoS One, Mitterer and McQueen (2009) investigated whether subtitles, which provide lexical information, support perceptual learning about foreign speech. Dutch participants, unfamiliar with Scottish and Australian regional accents of English, watched Scottish or Australian English movies with Dutch, English or no subtitles, and then repeated audio fragments of both accents. Repetition of novel fragments was worse after viewing movies with Dutch-subtitle but better after watching movies with English-subtitle. Native-language subtitles appear to create lexical interference, but foreign-language subtitles assist speech learning by indicating which words (and sound) are being spoken.

A study by Hayati and Mohmedi (2009) represented a preliminary effort to empirically examine the efficacy of subtitled movie on listening comprehension of intermediate English as Foreign Language students. To achieve this purpose, out of a total of 200 intermediate students, 90 were picked based on a proficiency test. The material consisted of six episodes (approximately 5 minutes each) of a DVD entitled Wild Weather. The students viewed only one of the three treatment conditions: English subtitles, Persian subtitles, no subtitles. After each viewing session, six sets of multiple-choice tests were administered to examine listening comprehension rates. The results revealed that the English subtitles group performed at a considerably higher level than the Persian subtitles group, which in turn performed at a substantially higher level than the no subtitle group on the listening test.

To summarize, most of the studies mentioned so far, seem to confirm that subtitles can improve language learning, vocabulary acquisition and content comprehension.

\section{Methodology}

\subsection{Participants}

This study involved 44 undergraduate students aged between 20-27 selected from senior students in the autumn semester of 2010. They were both male and female and were English Translation majors from two intact classes of Tapes and Films Translation course at Shiraz Islamic Azad University. Common to all of the participants was at least six years of exposure to EFL instruction during which they had learned English. With regard to nationality and language background no difference existed among the participants; all were Iranians and their mother tongue was Persian. Furthermore, none of the participants had lived in any English speaking country.

\subsection{Materials}

Two BBC documentary movies, one with English subtitles and the other without subtitles, were selected for this investigation. The one with subtitles was 'Dangerous Knowledge', about a mathematics professor, Georg Cantor, who started a revolution he never really meant to start. It eventually threatened to shake the whole of mathematics and science on its foundations. He started this revolution by asking himself a simple question: 'How 
big is infinity?'. This movie took about thirty minutes to play. The other movie without subtitling was called 'Where's my robot?', which introduced different kinds of robots. The duration of this film was twenty minutes.

The movies were selected based on the content to be interesting, the level of difficulty of the language to be appropriate for the participants and the duration of the films to be less than thirty minutes.

\subsection{Instruments}

Two different tests were used for each movie to collect the data. A set of ten multiple choice comprehension questions and another ten multiple choice vocabulary questions were developed by the researcher for each movie. These are four-choice questions and were extracted from the movies (Appendices A \& B). For the comprehension questions, first the researcher had to watch the whole movies to realize the theme and the subject. Then, she watched them carefully part by part to pose the comprehension four-choice questions. The advanced vocabulary was chosen from the movies for the vocabulary questions. Some of the sentences for the related vocabulary were extracted from Cambridge and Oxford Advanced Learners' Dictionary. To estimate the reliability of the tests, SPSS was used. The reliability for the comprehension and vocabulary items (subtitle and without) was calculated as .756 which is acceptable for a test of this kind.

\subsection{Procedure}

\subsubsection{Data Collection}

The participants were informed about the research project before the administration so as to stir motivation and interest. First, both classes watched the same movies, but group 1 first watched 'Dangerous knowledge' with English subtitling and then 'where's my robot?' without subtitling. To counteract the order effect the second group first watched 'where's my robot?' without subtitling, then 'Dangerous knowledge' with English subtitling. The movies were presented in one session. Then, after watching the movies, the participants of both classes received tests of vocabulary and content comprehension. After the first movie was played, students received a set of twenty multiple choice comprehension and vocabulary questions related to the movie, they had 15 minutes to answer the questions. Then, the second movie was played and following it the related questions were answered in 15 minutes.

\subsubsection{Scoring and Data analysis}

Data in this study consisted of the answers to the multiple choice comprehension and vocabulary recognition questions. The participants received one point for each item answered correctly. The data gathered were subjected to the statistical procedures of SPSS. First the scores were computed. Each participant had two scores, one for the movie with subtitle, and the other for the one without subtitle. Then, these two scores were categorized into four groups, including comprehension / vocabulary, and subtitle / without subtitle. In order to compare each participant's grade in one subcategory to their grade in another subcategory paired samples $t$-test was run to calculate the significance of the difference between the means of the two sets of scores. The four categories were total scores, comprehension with subtitle scores and comprehension without subtitle scores, vocabulary with subtitle scores and vocabulary without subtitle scores. In the following chapter the results of the analysis will be presented and discussed.

\subsection{Design of the Study}

The design of this research is one-shot case study; since, there was only one group without control one and also no pretest was run.

\section{Results and Discussion}

\subsection{Results}

To understand the participants' performance on the experimental task of the study, the statistical program of SPSS was used. Paired samples $t$-test was run to calculate the significance of the difference between the means of two sets of scores among three categories as presented below:

Subtitle and without subtitle scores, comprehension with subtitle scores and comprehension without subtitle scores, vocabulary with subtitle scores and vocabulary without subtitle scores.

\subsection{Discussion}

Referring to Table 1 the main effect obtained is that the participants performed better when the movie was played with bimodal subtitling. This includes total vocabulary and comprehension questions. The second row of this table deals with comprehension questions; in this row the results are better than the total. It can be said that the participants did actually perform better on comprehending the English movie with subtitle than the one 
without subtitle. However, there isn't any significant difference between watching a movie with subtitle and without for understanding the vocabulary of the movies. Therefore, our participants were more successful in comprehending the English movie with bimodal subtitling than without subtitling, since the written forms of the dialogues were presented to them. However, in the case of vocabulary viewing movie with subtitle had no particular effect, due to the fact that learning vocabulary from subtitled movies may need watching the film more than once.

\section{Conclusion}

This research on watching English movies with bimodal subtitling has shown that films are not only a means of motivation to entertain students, but also they could assist learners to comprehend the language as spoken in various accents. That is, EFL learners in general are exposed to the authentic language uttered by people with different accents in various parts of the United States and United Kingdom. Therefore, it is hard for learners to hear every single word, because they are used to the Standard English. Furthermore, this is a useful practice to get acquainted with different accents of English around the world, and bimodal subtitling is a perfect choice to assist the comprehension of the movies.

However, in this research bimodal subtitling had no effect on L2 vocabulary recognition, due to the fact that expose to the film once had probably no effect on vocabulary learning. Since, as Koolstra and Beentjes (1999) claimed, for learning vocabulary from subtitled movies students have to watch them with high frequency. It can be assumed that subtitled movies could have an effect on vocabulary recognition if learners watch the movie more than once. Viewing the movie twice or more may help students recognize vocabulary and they may learn new expressions and idioms.

\section{References}

Bird, S. A. \& Williams, J. N. (2002). The effect of bimodal input on implicit and explicit memory: An investigation into the benefits of within-language subtitling. Applied Psycholinguistics, 23(4), 509-533. [Online] Available: http://people.pwf.cam.ac.uk/jnw12/subtitling.pdf (September 26, 2010)

Borras, I. \& R.G. Lafayette. (1994). Effects of multimedia courseware subtitling on the speaking performance of college students of French. The Modern Language Journal, 78(1), 66-75. [Online] Available: http://www.jstor.org/pss/329253 (September 26, 2010)

Grgurović, M. \& Hegelheimer, V. (2007). Help options and multimedia listening: Students' use of subtitles and the transcript. Language Learning \& Technology, 11(1), 45-66. [Online] Available: http://ltt.msu.edu/vol1 1 num1/pdf/grgurovic.pdf (September 26, 2010)

Grignon, P., J. M. Lavaur \& N. Blanc. (2005). The effect of subtitles on film understanding. [Online] Available: sites.google.com/site/jeanmarclavaur/grigronlavaurblanc2007.pdf (April 29, 2010)

Hayati, M. \& Mohmedi, F. (2009). The effect of films with and without subtitles on listening comprehension of EFL learners. British Journal of Educational Technology. http://dx.doi.org/10.1111/j.1467-8535.2009.01004.x

Hinkin, M. (2009). Comprehension of multiple channel messages: Are subtitles more beneficial than soundtracks? [Online] Available: http://krex.kstate.edu/dspace/bitstream/2097/1679/1/MichaelHinkin2009.pdf (September 26, 2010)

Katchen, J. E., Lin, L. Y., Fox, T. \& Chun, V. (2002). Developments in Digital Video. [Online] Available: http://mx.nthu.edu.tw/ katchen/professional/developments\%20in\%20digital\%20video.htm (August 11, 2010)

King, J. (2002, February). Using DVD feature films in the EFL classroom. ELT Newsletter, The weekly column, Article 88. [Online] Available: http://www.eltnewsletter.com/back/February2002/art882002.htm (January 5, 2010)

Koolstra, C. M. \& J. W. J. Beentjes. (1999). Children's vocabulary acquisition in a foreign language through watching subtitled television programs at home. Educational Technology Research and Development, 47(1), 51-60. [Online] Available: http://www.springerlink.com/content/7951541774721423/ (August 11, 2010)

Kusumarasdyati. (2005). Subtitled Movie DVDs in Foreign Language Classes. Monash University. [Online] Available: http://www.aare.edu.au/06pap/kus06105.pdf (April 29, 2010)

Mitterer, H. \& McQueen, J. M. (2009). Foreign subtitles help but native-language subtitles harm foreign speech perception. [Online] Available: http://www.plosone.org/article/info:doi/10.1371/journal.pone.0007785 (January $5,2010)$ 
National Center for Technology Innovation and Center for Implementing Technology in Education (CITEd). (2010). Captioned Media: Literacy Support for Diverse Learners. [Online] Available: http://www.readingrockets.org/article/35793 (September 26, 2010)

Stewart, M. \& Pertusa, I. (2004). Gains to language learners from viewing target language closed-captioned films. Foreign Language Annals, 37(3), 438-447. http://dx.doi.org/10.1111/j.1944-9720.2004.tb02701.x

Zanon, N. T. (2006). Using subtitles to enhance foreign language learning. Porta Linguarum 6. [Online] Available: http://www.ugr.es/ portalin/articulos/PL_numero6/talavan.pdf (September 29, 2010)

\section{Appendix A}

Part A: Comprehension

1. Who was Georg Cantor?
a) A philosopher
c) A mathematician
b) A physicist
d) A scientist

2. Cantor started the revolution by asking the question
a) What is infinity?
c) Is there any infinity?
b) How big is infinity?
d) How can infinity be proved?

3. What is Cantor's last major publication about?
a) Set theory
c) Continuum hypothesis
b) Infinite theory
d) Modern mathematics

4. What did Cantor find after his first publication?
a) Infinity is a vague number without end.
b) He could not prove continuum hypothesis.
c) Set theory is not true.
d) He could add and subtract infinity.

5. When was the happiest and most inspired period of Cantor's life?

When .......
a) his theory came into publication.
b) he discovered there was a vast mathematics of the infinite.
c) he came to the Alps to meet a mathematician.
d) he proved the continuum hypothesis.

6. Where did Cantor spend his entire professional life?
a) In the asylum
c) In the lecture theater in the university
b) In the Alps
d) In his hometown, Hallie

7. What was Cantor's dream?
a) To prove continuum hypothesis
b) To receive an invitation to one of the great universities
c) To publish his work
d) To meet his friend in the Alps

8. What did his one time friend and teacher, Kronecker, say about Cantor?

He said he was
a) a corrupter of youth
c) the father of mathematics
b) a math sicker
d) a great scientist 
9. What is the most precious possession of Cantor's?
a) His publication
c) His continuum hypothesis
b) His father's letter
d) His set theory

10. Which statement is not true about Cantor?

a) He proved the continuum hypothesis.

b) He worked on the continuum hypothesis for the rest of his life.

c) He had the musical talent.

d) He never fully recovered.

\section{Part B: Vocabulary}

1. Most of the people are in the of happiness in their lives; some will reach it but others won't.
a) realm
b) tinge
c) pursuit
d) haste

2. When questioned by the police, the suspect, who had actually committed the crime, gave his questioners ..... insubstantial answer.
a) elusive
b) reticent
c) furtive
d) rudimentary

3. I think I managed to the main points of the lecture.
a) detain
b) grasp
c) deter
d) glance

4. They showed obvious hostility towards their new neighbors.
a) hospitality
b) hatred
c) havoc
d) humility

5. The government is planning to a bench marking scheme to guide consumers.
a) excel
b) launch
c) abolish
d) alter

6. Most of the students living in the dormitory in Iran have many adversities, which they have to overcome.
a) nuances
b) differences
c) pretexts
d) difficulties

7. It took a lot of to stand up and criticize the chairman.
a) asperity
b) brutality
c) audacity
d) brevity

8. We are affected by what happens to us in childhood.
a) interminably
b) profoundly
c) indiscriminately
d) pragmatically

9. On this occasion we pay to him for his achievements.
a) homicide
b) budget
c) homage
d) blunder

10. We've got a long way to go before we unravel the secrets of genetics.
a) abandon
b) conceal
c) reveal
d) blend

\section{Appendix B}

Part A: Comprehension

1. What did Danny quest for?

The robot.
a) beautiful
c) perfect
b) intelligent
d) walking

2. Which robot was in the Stanford University lab?
a) Stair
c) HRP3
b) Domo
d) Robotic 101

3. Why didn't Andrew tell Danny that Stair could talk? Because he
a) thought Danny might know it
c) forgot to do so
b) thought it was something ordinary
d) wanted to surprise him

4. Why did Danny come to Japan?

Because 
a) there were lots of robots there

b) many Japanese worked on robots

c) Japanese were famous for making complex robots

d) highly intelligent scientists were in Japan

5. Why did Danny show us a little Samurai robot on the train?

To indicate that
a) a robot could walk
b) a robot could be small
c) a robot could do what you wanted it to do
d) Japanese have made humanoid robots for many years

6. Why is HRP3 unique in walking robots?

Because
a) It can turn around
b) It doesn't need to be pre-programmed
c) It can both talk and walk
d) If it falls down, it can get up by itself

7. Where is HRP3 supposed to work?
a) In the office
c) In construction
b) In surgery
d) In the laboratory

8. Which statement is NOT true about HRP3?
a) It is very expensive.
b) It can tackle a large bump.
c) It is a robust manual worker.
d) It is a super robot.

9. Why does Domo need a vision system?
a) To recognize human faces
b) To detect color objects
c) To make sense of the world
d) To walk through rough surfaces

10. According to Danny, what is a crucial skill for robots if they are to do our bidding?
a) Moving around
b) Recognizing human faces
c) Talking and feeling
d) Making sense of the world

Part B: Vocabulary

Seeing that her husband was coming, she hastily changed the subject.
a) interminably
b) permanently
c) inexorably
d) promptly

Nothing will stop them in their for truth.
a) quest
b) embrace
c) quiver
d) endure

The talks ended abruptly when one of the delegates walked out in protest.
a) unexceptionally
b) unfoundedly
c) unexpectedly
d) unfairly

That's weird, I thought I'd left my keys on the table but they're not there.
a) funny
b) interesting
c) odd
d) annoying

This glass has been used, please me a clean one. 

a) fend
b) feud
c) flay
d) fetch

Her bicycle hit a in the road and threw her off.
a) clamp
b) bump
c) clique
d) baffle

Early of the cancer improves the chances of successful treatment.
a) expansion
b) depiction
c) estimation
d) detection

My father asked me to do my mother's after his departure.
a) braiding
b) besiege
c) bidding
d) binding

Take care when you walk on that path, the paving stones are rather
a) unformed
b) unbroken
c) uncovered
d) uneven

Jack watches at least two movies a day, in fact he is a movie
a) fanatic
b) critic
c) fringe
d) cripple

Table 1. $t$ values for the difference between the means of participants' two sets of scores

\begin{tabular}{|c|c|c|c|c|c|}
\hline & & Mean difference & $\mathrm{t}$ & $\mathrm{df}$ & Sig. (2-tailed) \\
\hline Pair 1 & total & 1.02273 & 2.475 & 43 & .017 \\
\hline Pair 2 & $\begin{array}{l}\text { comp }(+ \text { sub })- \\
\text { comp }(-\mathrm{sub})\end{array}$ & 1.47727 & 4.650 & 43 & .000 \\
\hline Pair 3 & $\begin{array}{l}\text { vocab (+sub)- } \\
\text { vocab (-sub) }\end{array}$ & -.45455 & -1.690 & 43 & .098 \\
\hline
\end{tabular}

According to Table 1 the value of $t$ for total vocabulary and comprehension questions was statistically significant $(t=2.475 \mathrm{p}<.017)$. It means that there is a significant difference between the two means. In other words participants answered the subtitled movie questions better than the questions of the movie without subtitle. Based on this table the value of $t$ for comprehension was more statistically significant than total $(t=4.650$ $\mathrm{p}<.000)$. These results showed that participants comprehended the subtitled movie better than the one without subtitle. However, there isn't any significant difference between the two means for vocabulary. 